○

\title{
Risk factors and mortality associated with undertriage at a level I safety-net trauma center: a retrospective study
}

This article was published in the following Dove Press journal:

Open Access Emergency Medicine

8 November 2016

Number of times this article has been viewed

\section{Chris Barsi \\ Peter Harris \\ Rich Menaik \\ Nicholas C Reis \\ Swapna Munnangi \\ Mikhail Elfond \\ Department of Emergency Medicine, Nassau University Medical Center, \\ East Meadow, NY, USA}

Correspondence: Swapna Munnangi Department of Emergency Medicine, Nassau University Medical Center, 220I Hempstead Turnpike, East Meadow, NY II554, USA

Tel +I 5165726833

Fax +I 5165725465

Email smunnang@numc.edu
Purpose: The primary objective of this study was to determine the risk factors associated with undertriage and the risk factors for mortality among the undertriaged patients at a level I safety-net trauma center.

Methods: A retrospective analysis was performed of all trauma patients who presented to a level I safety-net trauma center with an injury severity score $>15$ over a 2-year period (2013-2014). Univariate and multivariate regression analyses were used to determine the risk factors predictive of undertriage in major trauma patients (injury severity score $>15$ ) and of mortality in undertriaged patients.

Results: During the 2-year study period, 334 of 2,485 admitted trauma patients presented with major trauma and were included in our study. From the univariate analysis, variables that were found to be independently associated with mortality in undertriaged patients included intubation, Glasgow Coma Scale score, revised trauma score, and dementia. Independent risk factors that were found to be significantly associated with undertriage in severely injured trauma patients included Glasgow Coma Scale score, motor vehicle crash, falls, revised trauma score, systolic blood pressure, heart rate, intubation, and dementia. When a multivariate analysis was performed to evaluate the statistically significant risk factors, dementia was found to be significantly associated with undertriage in severely injured trauma patients.

Conclusion: Severely injured trauma patients with dementia are at significant risk for undertriage. Early identification of these risk factors while triaging at a level I safety-net trauma center could translate into improved patient outcomes following severe trauma.

Keywords: dementia, multi-tier trauma team activation, injury severity score, trauma activation guidelines

\section{Introduction}

The establishment of early and definitive trauma care by means of appropriate triage decreases mortality in traumatically injured patients. ${ }^{1,2}$ Trauma centers implement guidelines designed to match patient injury with hospital resources, in order to maximize efficient and effective care. ${ }^{3,4}$ Triage to a trauma center is guided by physiologic criteria, anatomic criteria, and the mechanism of injury. Our center has adopted a three-level trauma activation system detailed in Table S1.

In USA, the American College of Surgeons (ACS) provides oversight and accreditation for trauma centers. The ACS suggests that patients with major trauma receive the highest level of resources, as defined in Table S1. ${ }^{5,6}$ An injury severity score (ISS) can be calculated to quantify the severity of patient injuries. ${ }^{7}$ Major trauma is then defined as patients with an ISS $>15$. Because ISS is a retrospective scoring system, 
it cannot be used for triage of the acutely injured patient. Instead, trauma activation guidelines attempt to match the severity of the traumatic injury with the appropriate amount of resources. Ideally, patients with major trauma are triaged to the highest level of trauma care, that is, a level I trauma team activation (TTA), based on triage guidelines. However, some patients who present with certain risk factors are not assigned a level I TTA despite the severity of injuries. ${ }^{8}$ The group of patients with an ISS $>15$ who do not receive level I TTA are termed "undertriaged".

Several authors have demonstrated that undertriaged patients tend to have worse outcomes than appropriately triaged patients, ${ }^{9-11}$ including increased mortality. ${ }^{12,13}$ Hence, the ACS encourages the trauma centers to achieve an undertriage rate less than $5 \%$. However, in practice, the undertriage rate approaches $35 \%$ in the US. ${ }^{14,15}$ Risk factors for undertriage that were previously identified include: advanced age, female sex, and falls. ${ }^{12,14-17}$ However, only a few studies have looked at undertriaged patients within a multi-tiered trauma system. Further, this data is lacking in publicly owned hospitals which constitute $35 \%$ of level I trauma centers in the US. ${ }^{2}$ In the US, specialized level I trauma centers are accredited for the highest level of care for traumatic injuries. Further, publicly owned hospitals comprise a "public safety-net", which the Institute of Medicine defines as hospitals that deliver care to uninsured, underinsured, and vulnerable patients. ${ }^{18}$

In light of the paucity of data, the purpose of this study is to determine the risk factors for undertriage and mortality in a level I public safety-net trauma center. Determining these factors is especially important in safety-net hospitals, as they have been previously reported to be providing lower quality of care relative to non-safety-net hospitals. ${ }^{19}$ In addition, early detection of these risk factors while triaging could significantly improve the level of care provided, thereby improving patient outcomes and reducing mortality following severe trauma. ${ }^{20,21}$ Examining the demographics, injury characteristics, admission vitals, and mortality of trauma patients in a safety-net hospital could elucidate the risk factors that are most predictive of undertriage.

\section{Methods}

This retrospective analysis was conducted at Nassau University Medical Center (NUMC), a 500-bed level I safety-net trauma center in Nassau County, New York with approximately 1,650 trauma admissions per year. The trauma registry and patient medical records were used to identify all adult trauma patients (age $\geq 18$ years) who were admitted to the trauma center with an ISS $>15$ during a 2-year period (2013-2014). All data were obtained from the trauma registry and a standardized trauma flowsheet using the patient's medical record. Fifteen trauma patients who were pronounced dead upon arrival to the hospital were excluded from our study. Each injured body region of the trauma patient was assigned an Abbreviated Injury Scale score. The ISS score was calculated by adding together the square of Abbreviated Injury Scale scores for the three most severely injured body regions. ${ }^{22}$ During the 2-year study period, 334 patients had been admitted to our trauma center with an ISS $>15$. The study protocol was approved by the Institutional Review Board at NUMC. The Institutional Review Board at NUMC did not require that formal consent be obtained from the participants, due to the retrospective nature of this study.

At NUMC, the trauma patients are categorized according to the severity of injury and the following three-tier activation system: level I trauma indicates the most severe injuries and an allocation of the highest level of resources, level II TTA requires fewer members of the trauma team, and a level III TTA requires only a small portion of the trauma team and necessitates the fewest resources. The triage criteria and the team compositions for the activation levels are presented in Table S1. For the purpose of our study, undertriaged patients were those who presented with an ISS $>15$, but were not assigned a level I TTA in accordance with the Cribari method (Table S2). The trauma registry and the patient medical records were reviewed for patient demographic data and variables such as age, sex, race, injury characteristics, admission vitals, in-hospital complications, and mortality.

\section{Statistical analysis}

Descriptive statistics were performed on all variables in this study. Continuous variables were summarized as mean \pm standard deviation. Categorical variables were summarized as frequency distributions and percentages. Pearson's chisquared test or Fisher's exact test was used to compare categorical variables. Student's $t$-test or Mann-Whitney $U$-test was used to compare continuous variables. Univariate and multivariate regression analyses were used to determine the risk factors predictive of undertriage in severely injured trauma patients and of mortality in undertriaged patients. $P<0.05$ was considered statistically significant. SAS 9.4 was used as the statistical tool for analysis.

\section{Results}

During the 2-year study period (2013-2014), 2,485 patients were admitted to our trauma center. Of these, 334 (13.44\%) patients had an ISS $>15$, indicating major trauma. Among these major trauma patients, $171(51.20 \%)$ patients were appropriately triaged and $163(48.80 \%)$ patients were undertriaged. Using the Cribari method, the undertriage rate was $9.35 \%$ and 
the overtriage rate was $69.95 \%$. Baseline characteristics of the study population with the subgroups of patients that were appropriately triaged and undertriaged are presented in Table 1.

Patients who were undertriaged when compared to patients that were appropriately triaged had a significantly lower mortality rate $(7.36 \%$ vs $26.32 \% ; P=0.0001)$ and shorter intensive

Table I Demographic characteristics of the study population

\begin{tabular}{|c|c|c|c|}
\hline Variable & $\begin{array}{l}\text { Level I } \\
(n=|7|)\end{array}$ & $\begin{array}{l}\text { Undertriage } \\
(n=163)\end{array}$ & $P$-value \\
\hline Age (years), mean $\pm S D$ & $50.77 \pm 24.08$ & $53.59 \pm 25.37$ & 0.2977 \\
\hline \multicolumn{4}{|l|}{ Sex, n (\%) } \\
\hline Female & 55 (32.16\%) & 52 (31.90\%) & 0.9591 \\
\hline Male & I I 6 (67.84\%) & III (68.I0\%) & \\
\hline Race, n (\%) & & & 0.3223 \\
\hline White & $109(63.74 \%)$ & $93(57.06 \%)$ & \\
\hline Black & 20 (II.70\%) & 31 (19.02\%) & \\
\hline Hispanic & 30 (I7.54\%) & 28 (17.18\%) & \\
\hline Asian & $3(1.75 \%)$ & $3(1.84 \%)$ & \\
\hline Other & $9(5.26 \%)$ & $8(4.91 \%)$ & \\
\hline \multicolumn{4}{|l|}{ Type of injury, n (\%) } \\
\hline Blunt & 165 (96.49\%) & I 43 (87.83\%) & $0.0054 *$ \\
\hline Penetrating & $6(3.51 \%)$ & $20(12.27 \%)$ & \\
\hline Mechanism of injury, n (\%) & & & 0.1989 \\
\hline Motor vehicle crash & $44(25.73 \%)$ & 61 (37.42\%) & \\
\hline Falls & 82 (47.95\%) & 38 (23.3।\%) & \\
\hline Pedestrian struck & $37(21.64 \%)$ & $23(14 . \mid 1 \%)$ & \\
\hline Bicyclist & $4(2.34 \%)$ & $3(1.84 \%)$ & \\
\hline Gunshot wounds & $0(0.00 \%)$ & I8 (I I.04\%) & \\
\hline Fight/brawl & $0(0.00 \%)$ & $5(3.07 \%)$ & \\
\hline Assault & $0(0.00 \%)$ & 8 (4.9l\%) & \\
\hline Stab wounds & $4(2.34 \%)$ & I $(0.79 \%)$ & \\
\hline Other & $0(0.00 \%)$ & $5(3.07 \%)$ & \\
\hline ISS, median (IQR) & $25(19-34)$ & $18(17-24)$ & $<0.000 I^{*}$ \\
\hline GCS score, mean \pm SD & $10.15 \pm 5.06$ & $14.06 \pm 2.28$ & $<0.000 I^{*}$ \\
\hline $\begin{array}{l}\text { Revised trauma score, } \\
\text { mean } \pm \text { SD }\end{array}$ & $6.19 \pm 2.00$ & $7.63 \pm 0.72$ & $<0.000 I^{*}$ \\
\hline $\begin{array}{l}\text { Hospital LOS (days), } \\
\text { mean } \pm \text { SD }\end{array}$ & II.77 \pm 16.97 & $14.77 \pm 38.52$ & 0.3538 \\
\hline ICU LOS (days), mean \pm SD & $6.95 \pm 10.36$ & $4.72 \pm 8.29$ & $0.048 I *$ \\
\hline $\begin{array}{l}\text { ED LOS (in hours), } \\
\text { mean } \pm S D\end{array}$ & II.46士72.74 & $10.46 \pm 65.09$ & 0.8954 \\
\hline $\begin{array}{l}\text { Systolic blood pressure } \\
(\mathrm{mmHg}), \text { mean } \pm \mathrm{SD}\end{array}$ & $126.40 \pm 40.34$ & $141.94 \pm 28.62$ & $<0.000 I^{*}$ \\
\hline $\begin{array}{l}\text { Respiration rate (bpm), } \\
\text { mean } \pm \text { SD }\end{array}$ & I7. I I \pm 7.07 & $19.14 \pm 5.28$ & 0.0033 \\
\hline $\begin{array}{l}\text { Body temperature }\left({ }^{\circ} \mathrm{C}\right) \\
\text { mean } \pm S D\end{array}$ & $36.33 \pm 1.24$ & $36.56 \pm 0.46$ & 0.0477 \\
\hline $\begin{array}{l}\text { Heart rate (beats per min), } \\
\text { mean } \pm S D\end{array}$ & $92.70 \pm 28.08$ & $88.10 \pm 18.27$ & 0.0783 \\
\hline Intubation rate & $4 I(23.98 \%)$ & $3(1.84 \%)$ & $<0.0001 *$ \\
\hline Dementia & $6(3.51 \%)$ & 13 (7.98\%) & 0.0781 \\
\hline In-hospital complications & 42 (24.7I\%) & $25(15.34 \%)$ & $0.0405^{*}$ \\
\hline In-hospital mortality & 45 (26.32\%) & $12(7.36 \%)$ & $0.0001 *$ \\
\hline
\end{tabular}

Notes: $* P<0.05$ is considered significant. Level I group refers to patients in which Level I trauma team was activated.

Abbreviations: bpm, breaths per minute; ED, emergency department; GCS, Glasgow Coma Scale; ICU, intensive care unit; IQR, interquartile range; ISS, injury severity score; LOS, length of stay; SD, standard deviation. care unit length of stay ( 6.95 vs 4.72 days; $P=0.0481$ ). No differences were observed in age, sex, hospital, and emergency room length of stays. Also, undertriaged patients had a significantly higher Glasgow Coma Scale (GCS) score (14.06 \pm 2.28 vs $10.15 \pm 5.06 ; P<0.0001)$, higher systolic blood pressure (141.94 $\pm 28.62 \mathrm{mmHg}$ vs $126.40 \pm 40.34 \mathrm{mmHg} ; P<0.0001$ ), higher respiration rate $(19.14 \pm 5.28$ vs $17.11 \pm 7.07$ breaths per minute; $P=0.0033)$, higher body temperature $\left(36.33 \pm 1.24^{\circ} \mathrm{C}\right.$ vs $\left.36.56 \pm 0.46^{\circ} \mathrm{C} ; P=0.0477\right)$, and lower in-hospital complication rate $(15.34 \%$ vs $24.71 \% ; P=0.0405)$, when compared to appropriately triaged patients (Table 1).

Injury patterns in the study population by triage type are depicted in Figure 1. Head injury constituted the most common injury in both the study subgroups. Facial $(30.41 \%$ vs $18.41 \% ; P<0.05)$ and abdominal/pelvic injuries $(42.69 \%$ vs $24.54 \% ; P<0.05)$ were significantly higher in those patients who had been appropriately triaged versus patients who had been undertriaged. In-hospital complications by triage type are presented in Figure 2. Sepsis was the most common

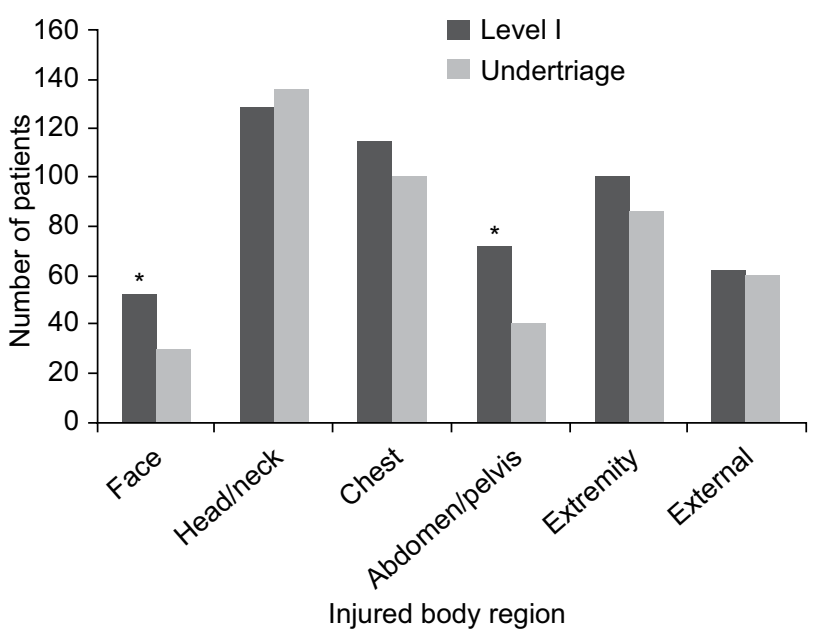

Figure I Body part injured by type of triage. $* p<0.05$.

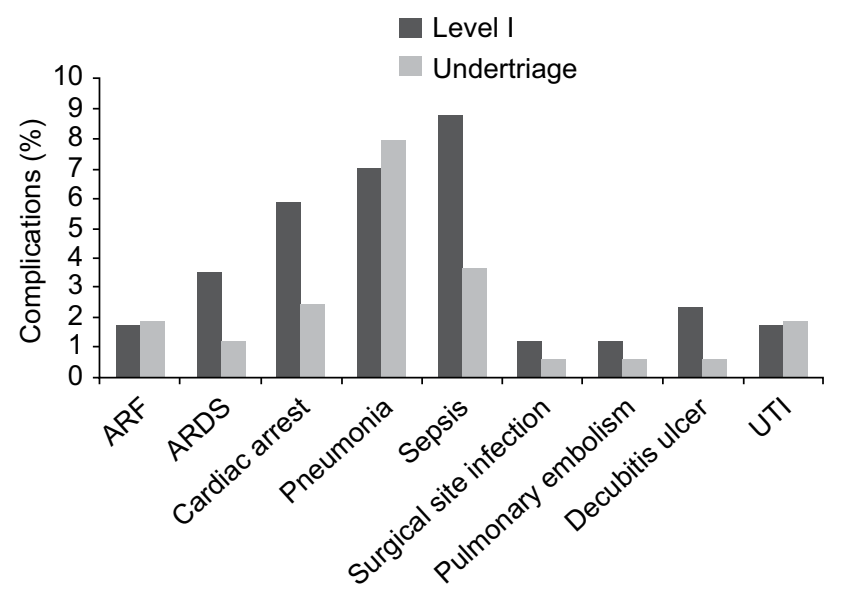

Figure 2 In-hospital complications by type of triage.

Abbreviations: ARDS, acute respiratory distress syndrome, ARF, acute renal failure; UTI, urinary tract infection. 
in-hospital complication in patients who had been appropriately triaged $(8.77 \%)$, whereas in undertriaged patients, it was pneumonia (7.98\%). Although the overall in-hospital complication rate was significantly lower in the undertriaged patients when compared to patients who had been appropriately triaged $(15.34 \%$ vs $24.71 \% ; P=0.0405)$, the types of complications observed were similar between the two groups.

From the univariate analysis (Table 2), variables that were found to be independently associated with mortality in undertriaged patients included intubation status (odds ratio $[\mathrm{OR}]=29.1,95 \%$ confidence interval $[\mathrm{CI}]=2.501-359.78$; $P=0.0073)$, GCS $(\mathrm{OR}=0.721,95 \% \mathrm{CI}=0.605-0.858$; $P=0.0002)$, ISS $(\mathrm{OR}=1.127,95 \% \mathrm{CI}=1.022-1.244$; $P=0.017)$, revised trauma score $(\mathrm{OR}=0.372,95 \% \mathrm{CI}=$ 0.200-0.694; $P=0.0019)$, and dementia $(\mathrm{OR}=4.7,95 \% \mathrm{CI}=$ 1.096-20.149; $P=0.0372$ ). After controlling for the confounding variables in the multivariate regression model, none of

Table 2 Univariate analysis of variables predictive of mortality in undertriaged patients

\begin{tabular}{llll}
\hline Variable & $\begin{array}{l}\text { Odds } \\
\text { ratio }\end{array}$ & $\mathbf{9 5 \% ~ C l}$ & P-value \\
\hline Age & 0.999 & $0.976-1.022$ & 0.9140 \\
Sex (female to male) & 2.283 & $0.699-7.454$ & 0.1717 \\
GCS score & 0.721 & $0.605-0.858$ & $0.0002^{*}$ \\
ISS & 1.127 & $1.022-1.244$ & $0.0170^{*}$ \\
Alcohol status & 0.332 & $0.041-2.672$ & 0.3003 \\
Drug status & 0.812 & $0.098-6.736$ & 0.8472 \\
Motor vehicle crash & 0.534 & $0.139-2.056$ & 0.3621 \\
Falls & 2.554 & $0.761-8.572$ & 0.1290 \\
Pedestrian struck & 2.392 & $0.813-10.572$ & 0.1002 \\
Revised trauma score & 0.372 & $0.200-0.694$ & $0.0019 *$ \\
Systolic blood pressure & 1.012 & $0.993-1.033$ & 0.2157 \\
Respiration rate & 0.936 & $0.773-1.135$ & 0.5026 \\
Heart rate & 1.028 & $0.993-1.064$ & 0.1137 \\
Body temperature & 0.719 & $0.376-1.374$ & 0.3176 \\
Intubation status & 29.100 & $2.501-359.78$ & $0.0073^{*}$ \\
Dementia & 4.700 & $1.096-20.149$ & $0.0372^{*}$ \\
\hline Note: & & &
\end{tabular}

Note: $* P<0.05$ is considered significant.

Abbreviations: $\mathrm{Cl}$, confidence interval; GCS, Glasgow Coma Scale; ISS, injury severity score.

Table 3 Multivariate analysis of variables predictive of mortality in undertriaged patients

\begin{tabular}{llll}
\hline Variable & $\begin{array}{l}\text { Odds } \\
\text { ratio }\end{array}$ & $\mathbf{9 5 \%} \mathbf{C l}$ & P-value \\
\hline Intubation status & $\mathrm{I} .165$ & $0.024-55.905$ & 0.9384 \\
GCS & $0.65 \mathrm{I}$ & $0.374-\mathrm{I} .133$ & 0.1289 \\
ISS & $\mathrm{I} .110$ & $0.985-1.25 \mathrm{I}$ & 0.0872 \\
Revised trauma score & $\mathrm{I} .669$ & $0.229-12.17 \mathrm{I}$ & 0.6134 \\
Dementia & 4.695 & $0.853-25.854$ & 0.0760 \\
\hline
\end{tabular}

Note: $* P<0.05$ is considered significant.

Abbreviations: $\mathrm{Cl}$, confidence interval; GCS, Glasgow Coma Scale; ISS, injury severity score. the independent variables were significantly associated with mortality in undertriaged patients (Table 3). Independent factors that were found to be significantly associated with undertriage in severely injured trauma patients (ISS $>15$ ) included GCS $(\mathrm{OR}=1.304,95 \% \mathrm{CI}=1.210-1.405 ; P<0.0001)$, motor vehicle crash $(\mathrm{OR}=1.726,95 \% \mathrm{CI}=1.082-2.754$; $P=0.0220)$, falls $(\mathrm{OR}=0.33,95 \% \mathrm{CI}=0.206-0.529$; $P<0.0001)$, revised trauma score $(\mathrm{OR}=2.436,95 \% \mathrm{CI}=$ $1.848-3.211 ; P<0.0001)$, systolic blood pressure $(\mathrm{OR}=$ $1.013,95 \% \mathrm{CI}=1.006-1.020 ; P=0.0001)$, and intubation $(\mathrm{OR}=0.059,95 \% \mathrm{CI}=0.018-0.196 ; P<0.0001)$ (Table 4$)$. When a multivariate analysis was performed to evaluate the statistically significant risk factors, falls (OR $=0.149,95 \%$ $\mathrm{CI}=0.071-0.312 ; P<0.0001)$, systolic blood pressure $(\mathrm{OR}=$ $1.020,95 \% \mathrm{CI}=1.009-1.031 ; P<0.0004)$, heart rate $(\mathrm{OR}=$ $0.979,95 \% \mathrm{CI}=0.965-0.994 ; P=0.0064)$, and dementia (OR $=11.384,95 \% \mathrm{CI}=1.537-84.305 ; P=0.0173$ ) were found to be the strongest predictors of undertriage in severely injured trauma patients (Table 5).

\section{Discussion}

Although the benefits of multi-tiered trauma systems have been previously identified, a significant portion of patients continue to be undertriaged, and thus, are potentially at risk for adverse outcomes. ${ }^{23,24}$ The observed undertriage rate of $9.35 \%$ at our center during the study period is higher than the ACS goal undertriage rate of $\leq 5 \% .{ }^{5}$ But it is difficult to compare the undertriage rates across studies owing to the differences in the definition of undertriage and institutional triage guidelines..$^{20,24,25}$ Unfortunately, the ACS gives little guidance on the definition or process for review of undertriage patients within the confines of a multi-tiered system. ACS considers any patient with an ISS $>15$ without a level I activation as undertriaged. Therefore, a patient with an ISS $>15$ and a level II TTA is technically undertriaged. On one hand, the presence of an attending surgeon has been reported to reduce resuscitation times. ${ }^{26,27}$ However, considerable resources are devoted to take care of injured patients with a level II activation (Table 1). The staffing for a level II trauma activation may be adequate for all, but the most severely injured trauma patients who need to be immediately taken to the operating room.

Ultimately, we have used the Cribari method which relies entirely on the ISS to calculate undertriage and overtriage rates. Paradoxically, the ISS itself cannot be used for triage and can only be calculated in retrospect after recognition of the full extent of the patient's injuries. Hence, the Cribari method does not take into consideration 
Table 4 Univariate analysis of variables predictive of undertriage in severely injured trauma patients

\begin{tabular}{|c|c|c|c|}
\hline Variable & $\begin{array}{l}\text { Odds } \\
\text { ratio }\end{array}$ & $95 \% \mathrm{Cl}$ & $P$-value \\
\hline Age & 1.005 & $0.996-1.013$ & 0.2967 \\
\hline Sex (female to male) & 0.988 & $0.624-1.565$ & 0.9591 \\
\hline GCS score & 1.304 & $1.210-1.405$ & $<0.000 I^{*}$ \\
\hline ISS & 0.876 & $0.843-0.910$ & $<0.000 I^{*}$ \\
\hline Alcohol status & 1.268 & $0.447-1.256$ & 0.2735 \\
\hline Drug status & 0.681 & $0.346-1.343$ & 0.2677 \\
\hline Motor vehicle crash & 1.726 & $\mathrm{I} .082-2.754$ & $0.0220 *$ \\
\hline Falls & 0.330 & $0.206-0.529$ & $<0.0001 *$ \\
\hline Pedestrian struck & 0.602 & $0.348-1.040$ & 0.0687 \\
\hline Stab wounds & 0.519 & $0.094-2.871$ & 0.4521 \\
\hline Injury class & 0.260 & $0.102-0.665$ & $0.0049 *$ \\
\hline Revised trauma score & 2.436 & $\mid .848-3.21 \mathrm{I}$ & $<0.000 I^{*}$ \\
\hline Systolic blood pressure & 1.013 & $1.006-1.020$ & $0.0001 *$ \\
\hline Respiration rate & 1.060 & $1.018-1.103$ & $0.0046^{*}$ \\
\hline Heart rate & 0.992 & $0.983-1.001$ & 0.0802 \\
\hline Body temperature & 1.220 & $0.978-1.522$ & 0.0780 \\
\hline Intubation & 0.059 & $0.018-0.196$ & $<0.000$ I* $^{*}$ \\
\hline Mental disorder & 0.914 & $0.324-2.581$ & 0.8658 \\
\hline Dementia & 2.383 & $0.883-6.427$ & 0.0863 \\
\hline
\end{tabular}

Note: $* P<0.05$ is considered significant.

Abbreviations: $\mathrm{Cl}$, confidence interval; GCS, Glasgow Coma Scale; ISS, injury severity score.

Table 5 Multivariate analysis of variables predictive of undertriage in severely injured trauma patients

\begin{tabular}{llll}
\hline Variable & $\begin{array}{l}\text { Odds } \\
\text { ratio }\end{array}$ & $\mathbf{9 5 \%} \mathbf{C l}$ & P-value \\
\hline GCS score & 1.277 & $0.996-1.636$ & 0.0540 \\
ISS & 0.918 & $0.878-0.959$ & $0.000 I^{*}$ \\
Revised trauma score & 0.954 & $0.44 I-2.064$ & 0.9056 \\
Falls & 0.149 & $0.07 I-0.312$ & $<0.000$ F $^{*}$ \\
Motor vehicle crash & 1.006 & $0.487-2.077$ & 0.9874 \\
Systolic blood pressure & 1.020 & $1.009-1.031$ & $0.0004^{*}$ \\
Respiration rate & 0.979 & $0.965-0.994$ & $0.0064^{*}$ \\
Intubation & 0.238 & $0.048-1.190$ & 0.0805 \\
Dementia & 11.384 & $1.537-84.305$ & $0.0173^{*}$ \\
\hline
\end{tabular}

Note: $* P<0.05$ is considered significant.

Abbreviations: $\mathrm{Cl}$, confidence interval; GCS, Glasgow Coma Scale; ISS, injury severity score.

the true process of triage whereby an institution develops criteria (Table S1) meant to guide the physician's clinical judgment. An alternative approach to define undertriage would be to examine those patients who did not get a full TTA despite fulfilling the institutional triage guidelines for a full TTA. As an example, a patient would be labeled undertriaged if he had a gunshot at the chest (an anatomic triage criteria in Table S1), but did not receive a level I TTA. In this schema, undertriage would not depend on ISS; instead, it would rely on how well the institutions executed their triage guidelines.
This study substantiates that ISS, lower GCS, revised trauma score, and intubation are predictors of mortality in all trauma patients, regardless of triage status. ${ }^{3}$ Furthermore, the lower mortality rate and the shorter intensive care unit length of stay in the undertriaged patients likely reflect the significantly lower ISS and higher GCS in this population. This finding is similar to other studies that seek to find factors related to undertriage. ${ }^{28,29}$ Undertriaged patients tend to have lower injury scores than TTA patients, and thus are expected to have better outcomes overall. However, individual undertriaged patients with injury scores similar to those of TTA patients are likely to become worse. Previous authors have explored this by analyzing predicted versus actual survival rates among undertriaged patients and appropriately triaged patients. Rainer et al found that undertriage only affected mortality when the patient had a moderate probability of death and it did not affect mortality when there was a small or large probability of death. ${ }^{30}$

The results of this study illustrated that patients with dementia were significantly more likely to be undertriaged. Furthermore, patients with dementia had significantly higher odds of death when undertriaged. After controlling for confounding variables, this trend remained, but was no longer statistically significant. Xiang et al found that elderly patients were more likely to be undertriaged and that more than $40 \%$ of undertriaged patients had a diagnosis of traumatic brain injury. ${ }^{14}$ These findings, in conjunction with our data, suggest careful examination of patients who have baseline cognitive impairment. This study did not specifically examine the degree of mental deficit or the functional status of dementia patients. Decreased communication ability of these patients may have contributed to undertriage; however, data limitations prevented the subset analysis of why dementia is a predictor of undertriage in these trauma patients. It is possible that an abnormal sensorium may have been inappropriately ascribed to their underlying dementia when, in fact, it was due to trauma.

Our findings suggest that providers should look more closely at trauma patients with a history of dementia and consider a lower threshold for level I TTA in these patients. However, the results should be interpreted in the context of a number of limitations. First, the study represents a relatively small sample size. Furthermore, patients with endof-life directives were not excluded from the study sample. Additionally, the results are from a single public safety-net trauma center and, therefore, may not be reflective of other institutions. Lack of consistent definition of undertriage in institutions with multi-tiered trauma systems prevents making valid comparisons among them. In this context, the findings 
of this study may assist in minimizing undertriage of severely injured trauma patients and enhancing the distribution of relatively scarce resources at a safety-net trauma center.

\section{Conclusion}

Most strikingly, our data showed that severely injured patients with dementia were more likely to be undertriaged. Further research may explore the reasons behind these observations, including the communication ability and the specific level of cognitive impairment of trauma patients with dementia. Improving awareness of the risk factors like dementia may positively impact the trauma triage process. Our data are also important as they are taken from a public safety-net hospital, which serves a population with poor access to primary care and often with financial instability. The findings will be especially useful to other health systems serving similar populations and can be broadened with future research.

\section{Acknowledgments}

The abstract of this paper was published in New York Chapter American College of Physicians, Resident and Medical Student Forum, Saturday, November 14, 2015, Medical Student Clinical Vignette, Medical Student Patient Safety \& Outcomes Measurement, Page 13 as an abstract with interim findings.

\section{Disclosure}

The authors report no conflicts of interest in this work.

\section{References}

1. Celso B, Tepas J, Langland-Orban B, Pracht E, Papa L, Lottenberg L, Flint L. A systematic review and meta-analysis comparing outcome of severely injured patients treated in trauma centers following the establishment of trauma systems. J Trauma. 2006;60(2):371-378.

2. MacKenzie EJ, Rivara FP, Jurkovich GJ, et al. A national evaluation of the effect of trauma-center care on mortality. $N$ Engl J Med. 2006;354(4):366-378.

3. Cherry RA, King TS, Carney DE, Bryant P, Cooney RN. Trauma team activation and the impact on mortality. JTrauma. 2007;63(2):326-330.

4. Lehmann RK, Arthurs ZM, Cuadrado DG, Casey LE, Beekley AC, Martin MJ. Trauma team activation: simplified criteria safely reduces overtriage. Am J Surg. 2007;193(5):630-634.

5. American College of Surgeons, Committee on Trauma. Resources for Optimal Care of the Injured Patient: 2014. Chicago: American College of Surgeons; 2014.

6. Kouzminova N, Shatney C, Palm E, McCullough M, Sherck J. The efficacy of a two-tiered trauma activation system at a level I trauma center. J Trauma. 2009;67(4):829-833.

7. Copes WS, Champion HR, Sacco WJ, Lawnick MM, Keast SL, Bain LW. The injury severity score revisited. J Trauma. 1988;28(1):69-77.

8. Shifflette VK, Lorenzo M, Mangram AJ, Truitt MS, Amos JD, Dunn EL. Should age be a factor to change from a level II to a level I trauma activation? J Trauma. 2010;69(1):88-92.

9. Petrie D, Lane P, Stewart TC. An evaluation of patient outcomes comparing trauma team activated versus trauma team not activated using TRISS analysis. Trauma and injury severity score. $J$ Trauma. 1996;41(5):870-873; discussion 873-875.
10. Wang C, Hsiao K, Shih H, Tsai Y, Chen I. The role of trauma team activation by emergency physicians on outcomes in severe trauma patients. J Acute Med. 2014;4(1):1-5.

11. Vickers BP, Shi J, Lu B, et al. Comparative study of ED mortality risk of US trauma patients treated at level I and level II vs nontrauma centers. Am J Emerg Med. 2015;33(9):1158-1165.

12. Rainer TH, Cheung NK, Yeung JH, Graham CA. Do trauma teams make a difference? A single centre registry study. Resuscitation. 2007;73(3):374-381.

13. Scarborough K, Slone DS, Uribe P, Craun M, Bar-Or R, Bar-Or D. Reduced mortality at a community hospital trauma center: the impact of changing trauma level designation from II to I. Arch Surg. 2008; 143(1):22-27; discussion 27-28.

14. Xiang H, Wheeler KK, Groner JI, Shi J, Haley KJ. Undertriage of major trauma patients in the US emergency departments. Am J Emerg Med. 2014;32(9):997-1004.

15. Staudenmayer K, Lin F, Mackersie R, Spain D, Hsia R. Variability in california triage from 2005 to 2009: A population-based longitudinal study of severely injured patients. J Trauma Acute Care Surg. 2014;76(4):1041-1047.

16. Kodadek LM, Selvarajah S, Velopulos CG, Haut ER, Haider AH. Undertriage of older trauma patients: Is this a national phenomenon? J Surg Res. 2015.

17. Chang DC, Bass RR, Cornwell EE, Mackenzie EJ. Undertriage of elderly trauma patients to state-designated trauma centers. Arch Surg. 2008;143(8):776-781; discussion 782.

18. Lewin M, Altman S, editors. Institute of Medicine (US) Committee on the Changing Market, Managed Care, and the Future Viability of Safety Net Providers. USA: National Academies Press; 2000.

19. Werner RM, Goldman LE, Dudley RA. Comparison of change in quality of care between safety-net and non-safety-net hospitals. JAMA. 2008;299(18):2180-2187.

20. Rogers A, Rogers FB, Schwab CW, Bradburn E, Lee J, Wu D, Miller JA. Increased mortality with undertriaged patients in a mature trauma center with an aggressive trauma team activation system. Eur J Trauma Emerg Surg. 2013;39(6):599-603.

21. Sasser SM, Hunt RC, Faul M, et al; Centers for Disease Control and Prevention (CDC). Guidelines for field triage of injured patients: recommendations of the national expert panel on field triage, 2011. MMWR Recomm Rep. 2012;61(RR-1):1-20.

22. Baker SP, O’Neill B, Haddon W,Jr, Long WB. The injury severity score: a method for describing patients with multiple injuries and evaluating emergency care. J Trauma. 1974;14(3):187-196.

23. Rehn M, Lossius HM, Tjosevik KE, et al. Efficacy of a two-tiered trauma team activation protocol in a norwegian trauma centre. $\mathrm{Br} J$ Surg. 2012;99(2):199-208.

24. Davis T, Dinh M, Roncal S, Byrne C, Petchell J, Leonard E, Stack A. Prospective evaluation of a two-tiered trauma activation protocol in an australian major trauma referral hospital. Injury. 2010;41(5): 470-474.

25. Nakahara S, Matsuoka T, Ueno M, Mizushima Y, Ichikawa M, Yokota J, Yoshida K. Predictive factors for undertriage among severe blunt trauma patients: What enables them to slip through an established trauma triage protocol? J Trauma. 2010;68(5):1044-1051.

26. Khetarpal S, Steinbrunn BS, McGonigal MD, et al. Trauma faculty and trauma team activation: Impact on trauma system function and patient outcome. J Trauma. 1999;47(3):576-581.

27. Tsang B, McKee J, Engels PT, Paton-Gay D, Widder SL. Compliance to advanced trauma life support protocols in adult trauma patients in the acute setting. World J Emerg Surg. 2013;8(1):39.

28. Eastes LS, Norton R, Brand D, Pearson S, Mullins RJ. Outcomes of patients using a tiered trauma response protocol. J Trauma. 2001;50(5):908-913.

29. Curtis K, Olivier J, Mitchell R, et al. Evaluation of a tiered trauma call system in a level 1 trauma centre. Injury. 2011;42(1):57-62.

30. Rainer TH, Ho AM, Yeung JH, et al. Early risk stratification of patients with major trauma requiring massive blood transfusion. Resuscitation. 2011;82(6):724-729. 


\section{Supplementary materials}

Table SI Trauma team activation criteria and trauma team composition

\begin{tabular}{|c|c|c|c|}
\hline Criteria & Level I & Level II & Level III \\
\hline Anatomic criteria & $\begin{array}{l}\text { Gunshot wounds to the neck, chest, or } \\
\text { abdomen } \\
\text { Hanging injury } \\
\text { Crushed, degloved, or pulseless } \\
\text { extremity or amputations, excluding } \\
\text { digits }\end{array}$ & $\begin{array}{l}\text { Severe facial fractures } \\
\text { Multiple extremity fractures }\end{array}$ & $\begin{array}{l}\text { Any stable patient with low likelihood } \\
\text { of significant injury being considered } \\
\text { for admission to the hospital }\end{array}$ \\
\hline Physiologic criteria & $\begin{array}{l}\text { Traumatic arrest } \\
\text { Systolic blood pressure }<90 \mathrm{mmHg} \\
\text { GCS score }<8 \\
\text { Intubated patients }\end{array}$ & None specified & \\
\hline Mechanism & $\begin{array}{l}\text { Falls }>6.096 \text { meters } \\
\text { High-risk auto crash - death in same } \\
\text { passenger compartment }\end{array}$ & $\begin{array}{l}\text { Falls }<6.096 \text { meters } \\
\text { Auto crash that includes: intrusion } \\
>0.305 \mathrm{~m}[12 \text { inches] on the occupant } \\
\text { side or }>0.457 \mathrm{~m}[18 \text { inches] any side } \\
\text { Ejection from automobile } \\
\text { Auto versus pedestrian/bicyclist } \\
\text { thrown, run over, or with significant } \\
(>32 \mathrm{kph}[>20 \mathrm{mph}]) \text { impact } \\
\text { Motorcycle crash }>32 \mathrm{kph}(20 \mathrm{mph}) \\
\text { Rollover }\end{array}$ & \\
\hline Special conditions & $\begin{array}{l}\text { Pregnancy }>20 \text { weeks } \\
\text { Patients with head injury at risk for rapid } \\
\text { deterioration (anticoagulants or bleeding } \\
\text { disorders) } \\
\text { Unstable pelvic fractures } \\
\text { EMS or emergency medicine physician } \\
\text { discretion }\end{array}$ & $\begin{array}{l}\text { Burns and explosion with potential } \\
\text { airway compromise } \\
\text { EMS or emergency medicine physician } \\
\text { discretion }\end{array}$ & \\
\hline Team composition & $\begin{array}{l}\text { Trauma attending } \\
\text { Emergency medicine attending } \\
\text { Anesthesia attending } \\
\text { PGY } 3,4 \text {, or } 5 \text { surgical resident } \\
\text { PGY } 2 \text { surgical resident } \\
\text { PGY I surgical resident } \\
\text { Emergency medicine resident } \\
\text { Two emergency department nurses } \\
\text { Respiratory therapist } \\
\text { Radiology technologist }\end{array}$ & $\begin{array}{l}\text { Emergency medicine attending } \\
\text { PGY } 3,4 \text {, or } 5 \text { surgical resident } \\
\text { PGY } 2 \text { surgical resident } \\
\text { PGY I surgical resident } \\
\text { Emergency medicine resident } \\
\text { Two emergency department nurses } \\
\text { Respiratory therapist } \\
\text { Radiology technologist }\end{array}$ & $\begin{array}{l}\text { Emergency medicine attending } \\
\text { PGY } 3,4 \text {, or } 5 \text { surgical resident } \\
\text { Emergency Medicine resident } \\
\text { Emergency Department nurse }\end{array}$ \\
\hline
\end{tabular}

Note: Levels I, II, and III refer to the level of response in the multi-tier trauma system.

Abbreviations: EMS, emergency medical service; GCS, Glasgow Coma Scale; PGY, postgraduate year.

Table S2 Cribari method (ACS)

\begin{tabular}{lllll}
\hline TTA level & ISS 0-I5 & ISS I6-75 & Total & \\
\hline $\begin{array}{l}\text { Level I trauma } \\
\text { activation }\end{array}$ & A & B & C & $\begin{array}{l}\text { Overtriage }= \\
\text { A } C \times 100\end{array}$ \\
$\begin{array}{l}\text { Level II or III trauma } \\
\text { activation }\end{array}$ & D & E & F & $\begin{array}{l}\text { Undertriage }= \\
\text { E/F } \times 100\end{array}$ \\
\hline
\end{tabular}

Notes: Levels I, II, and III refer to the level of response in the multi-tier trauma system. The activation criteria and team composition for each level is presented in Table SI. A, number of trauma patients with ISS 0-15 with Level I trauma activation. B, number of trauma patients with ISS 16-75 with Level I trauma activation. C, total number of patients with Level I trauma activation. D, number of trauma patients with ISS 0-15 with Level II or III trauma activation. E, number of trauma patients with ISS 16-75 with Level II or III trauma activation. F, total number of patients with Level II or III trauma activation.

Abbreviations: ACS, American College of Surgeons; TTA, trauma team activation; ISS, injury severity score. 


\section{Publish your work in this journal}

The Open Access Emergency Medicine is an international, peerreviewed, open access journal publishing original research, reports, editorials, reviews and commentaries on all aspects of emergency medicine. The manuscript management system is completely online and includes a very quick and fair peer-review system, which is all

Submit your manuscript here: https://www.dovepress.com/open-access-emergency-medicine-journal

easy to use. Visit http://www.dovepress.com/testimonials.php to read real quotes from published authors. 